\title{
EXECUÇÃO DOS LIMITES MÍNIMOS CONSTITUCIONAIS DE FINANCIAMENTO DA EDUCAÇÃO NOS MUNICÍPIOS DA MESORREGIÃO JEQUITINHONHA
}

\section{FULFILLMENT OF THE MINIMUM CONSTITUTIONAL LIMITS OF FINANCING EDUCATION IN THE MUNICIPALITIES OF THE MESORREGION JEQUITINHONHA}

\section{EJECUCIÓN DE LOS LÍMITES MÍNIMOS CONSTITUCIONALES DE FINANCIACIÓN DE LA EDUCACIÓN EN LOS MUNICIPIOS DE LA MESORREGIÓN JEQUITINHONHA}

\author{
Éder de Souza Beirão \\ Universidade Estadual de Montes Claros - UNIMONTES \\ E-mail: <ederbeirao@gmail.com>. \\ Marcos Esdras Leite (D) 9 \\ Universidade Estadual de Montes Claros - UNIMONTES \\ E-mail: <marcosesdrasleite@gmail.com>.
}

\begin{abstract}
RESUMO
O presente estudo tem como objetivo verificar a execução do art. 212 da Constituição Federal de 1988 nos municípios da mesorregião Jequitinhonha, no período que compreende os anos de 2000 a 2017. Foi utilizada como metodologia a pesquisa de abordagem quantitativa, classificada quantos aos objetivos em descritiva e quanto aos procedimentos em documental. A variável utilizada para a análise do cumprimento dos limites mínimos constitucionais da função Educação foi o orçamentário em atividades na área realizadas pelos municípios da mesorregião Jequitinhonha. Estes dados foram extraídos da plataforma intitulada Índice Mineiro de Responsabilidade Social (IMRS), da Fundação João Pinheiro (FJP). A partir dos resultados, foi possível inferir que grande parte dos municípios da mesorregião Jequitinhonha não cumpriu o limite mínimo constitucional da educação no período analisado. Apenas os municípios de Angelândia/MG, Divisópolis/MG, Minas Novas/MG e Ponto dos Volantes/MG não deixaram de cumprir o limite em nenhum dos anos da série histórica. Já o município de Diamantina/MG não conseguiu cumprir o limite mínimo da educação que é de $25 \%$, no período analisado. Em todas as microrregiões, é possível observar uma redução das porcentagens do esforço orçamentário com atividades da educação.
\end{abstract}


BEIRÃO, É. S.; LEITE, M. E.

Execução dos limites mínimos constitucionais de financiamento da educação nos municípios da mesorregião Jequitinhonha

Palavras-chave: Limite mínimo constitucional. Função Educação. Mesorregião Jequitinhonha.

\begin{abstract}
This study aims to verify the execution of art. 212 of the Federal Constitution of 1988 in the municipalities of the Jequitinhonha mesoregion, from 2000 to 2017. A quantitative approach research was used as a methodology, classified according to the descriptive objectives and the documentary procedures. The variable used for the analysis of compliance with the constitutional minimum limits of the Education function was the budget for activities in the area carried out by the municipalities of the Jequitinhonha mesoregion. These data were extracted from the platform entitled Minas Gerais Social Responsibility Index (IMRS), from the João Pinheiro Foundation (FJP). From the results, it was possible to infer that most of the municipalities of the Jequitinhonha mesoregion did not meet the constitutional minimum limit of education in the analyzed period. Only the municipalities of Angelândia/MG, Divisópolis/MG, Minas Novas/MG and Ponto dos Volantes/MG did not fail to meet the limit in any of the years of the historical series. Already the municipality of Diamantina/MG failed to meet the minimum limit of education that is $25 \%$ in the period analyzed. In all microregions, it is possible to see a reduction in the percentages of budget effort with education activities.
\end{abstract}

Keywords: Constitutional minimum limit. Function Education. Mesorregion Jequitinhonha.

\title{
RESUMEN
}

Este estudio tiene como objetivo verificar la ejecución del art. 212 de la Constitución Federal de 1988 en los municipios de la mesorregión Jequitinhonha, de 2000 a 2017. Se utilizó como método una investigación de enfoque cuantitativo, clasificada según los objetivos descriptivos y los procedimientos documentales. La variable utilizada para el análisis del cumplimiento de los límites mínimos constitucionales de la función Educación fue el presupuesto para actividades en el área llevadas a cabo por los municipios de la mesorregión de Jequitinhonha. Estos datos fueron extraídos de la plataforma titulada Índice de Responsabilidad Social de Minas Gerais (IMRS), de la Fundación João Pinheiro (FJP). A partir de los resultados, fue posible inferir que la mayoría de los municipios de la mesorregión de Jequitinhonha no alcanzaron el límite mínimo constitucional de educación en el período analizado. Solo los municipios de Angelândia/MG, Divisópolis/MG, Minas Novas/MG y Ponto dos Volantes/MG no dejaron de cumplir el límite en ninguno de los años de la serie histórica. El municipio de Diamantina/MG ya no cumplió con el límite mínimo de educación que es del $25 \%$ en el período analizado. En todas las microrregiones, es posible ver una reducción en los porcentajes de esfuerzo presupuestario con actividades educativas.

Palabras clave: Límite mínimo constitucional. Función Educación. Mesorregión Jequitinhonha. 
BEIRÃO, É. S.; LEITE, M. E.

Execução dos limites mínimos constitucionais de financiamento da educação nos municípios da mesorregião Jequitinhonha

\section{INTRODUÇÃO}

Atualmente, um dos maiores desafios impostos ao Estado é a efetivação dos direitos sociais, econômicos e culturais. O desafio se encontra na incerteza de que estes direitos possam ser prestados de forma plena e satisfatória a todos que deles efetivamente necessitem.

O Brasil, especificamente, tem sofrido com um novo contexto macroeconômico, o da restrição orçamentária que atinge bruscamente todos os setores, mais precisamente os sociais, como é o caso da saúde, educação, assistência social, previdência social, habitação, urbanização, cultura, segurança etc. Além disso, a nação brasileira tem passado por um intenso crescimento demográfico que tem agravado sua situação socioeconômica, pois acaba provocando aumento da demanda pela ação e por serviços ofertados pelo governo.

A crise em questão faz emergir a necessidade da elevação dos gastos públicos e de maiores repasses de recursos destinados às áreas sociais. Os gastos efetuados pelo governo afetam diversas atividades, algumas das quais, em dado momento, provavelmente, tiveram, tem ou terão algo a ver com a vida de todos os indivíduos integrantes da sociedade (STIGLITZ, 1986).

Há a necessidade de um gerenciamento mais eficiente e eficaz dos recursos públicos, especialmente, daqueles destinados à educação, uma vez que é um dos setores mais atingidos pela crise gerada pela restrição orçamentária. Este gerenciamento deve ocorrer no âmbito de todos os entes federados, sobretudo nos municípios (COSTA; CASTANHAR, 2003). Campos et al. (2014) afirma que os recursos destinados a Função Educação são provenientes da arrecadação pública do Imposto Predial e Territorial Urbano (IPTU), Imposto sobre transmissão "inter vivos", a qualquer título, por ato oneroso, de bens imóveis, por natureza ou acessão física, e de direitos reais sobre imóveis, exceto os de garantia, bem como cessão de direitos a sua aquisição (ITBI) e Imposto Sobre Serviços de Qualquer Natureza (ISSQN).

Visando um melhor gerenciamento dos recursos públicos destinados à Função Educação, a Constituição Federal de 1988 define todos os entes federados que devem aplicar uma porcentagem de suas receitas provenientes de impostos, taxas e contribuições de melhoria na Função Educação com o intuito da melhoria do ensino. No caso dos municípios, 
BEIRÃO, É. S.; LEITE, M. E.

Execução dos limites mínimos constitucionais de financiamento da educação nos municípios da mesorregião Jequitinhonha

a porcentagem é equivalente a $25 \%$. A determinação da Constituição é válida para os Estados e, no caso da União, o percentual mínimo de investimento na educação é de $18 \%$.

Considerando a importância da discussão acerca da execução limite mínimo constitucional da Função Educação, o presente trabalho tem o seguinte problema de pesquisa: o limite mínimo constitucional de financiamento da educação tem sido executado conforme o art. 212 da Constituição Federal nos Municípios da mesorregião Jequitinhonha?

$\mathrm{Na}$ busca de responder à questão norteadora traçada para o presente estudo, foi definido como objetivo geral verificar a execução do art. 212 da Constituição de 1988 nos Municípios da mesorregião Jequitinhonha, no período de 2000 a 2017.

O trabalho desenvolveu-se com a adoção dos seguintes procedimentos metodológicos: pesquisa quantitativa e descritiva, que utilizou como método o estudo de caso, o levantamento de dados secundários como fonte de coleta de dados e a pesquisa bibliográfica e documental para embasamento teórico do estudo, além da análise de dados secundários obtidos na plataforma do Índice Mineiro de Responsabilidade Social (IMRS), da Fundação João Pinheiro (FJP).

A fundamentação teórica encontra-se apoiada nas propostas de Heilio Kohama (2001), Roberto Bocaccio Piscitelli, Maria Zulene Farias Timbó e Maria Berenice Rosa (2002), Valmor Slomski (2008), Fábio Giambiagi e Ana Cláudia Duarte de Além (2011), Cézar Volnei Mauss (2012) e outros autores que contribuíram significativamente para a discussão aqui proposta.

\section{REVISÃO DE LITERATURA}

\section{Gastos Públicos}

Despesas públicas dizem respeito aos gastos fixados pela lei orçamentaria ou por leis especiais destinadas à execução de serviços públicos e aumentos patrimoniais, à satisfação dos compromissos da dívida pública ou a restituição ou pagamento de importâncias recebidas a título de cauções, depósitos, consignações etc (KOHAMA, 2001). Piscitelli, Timbó e Rosa (2002, p. 149) definem despesa pública como sendo todo "dispêndio de recursos do patrimônio público, representado essencialmente por uma saída de recursos 
BEIRÃO, É. S.; LEITE, M. E.

Execução dos limites mínimos constitucionais de financiamento da educação nos municípios da mesorregião Jequitinhonha

financeiros, imediata - com redução de disponibilidades - ou mediata - com reconhecimento dessa obrigação".

Apesar destas definições de despesa pública, o que se tem notado é uma mudança da visão e da nomenclatura dos dispêndios públicos. Mauss (2012, p. 79) enfatiza a mudança desta visão ao dizer que o que tem ocorrido é "uma ampliação do sentido deste termo para que se tenha de utilizar efetivamente a expressão gasto público, e não mais despesa apenas". O autor explica que a visão da despesa foi ampliada, percorrendo assim "todos os âmbitos contábeis - orçamentos, ativos e passivos - sendo considerada tanto na forma orçamentária, como extraorçamentária”.

Os gastos/despesas públicas podem ser estratificados em dois grupos: i) despesas orçamentárias; ii) despesas extraorçamentárias. O primeiro grupo é aquele que engloba as despesas que integram o orçamento, ou seja, aquelas que são discriminadas e fixadas no orçamento público. Já o segundo, traz as despesas que não estão vinculadas ao orçamento público, isto é, gastos que não necessitam ser empenhados (ANGÉLICO, 1994).

Mauss (2012, p.79) argumenta que no setor público surgirão situações em que os gastos não serão empenhados, portanto, não há enquadramento orçamentário e, por consequência, não ocorrerá a diminuição do patrimônio líquido. $\mathrm{O}$ autor, então, define o gasto público como sendo "todo aquele conjunto de valores realizado pelo Estado para manter o funcionamento dos serviços por ele prestados".

As despesas ou gastos públicos podem ser classificados de várias formas, conforme vários critérios. No Brasil, as classificações mais comumente utilizadas são as seguintes: i) categoria econômica; ii) classificação funcional-programática; iii) grupo de Natureza de Despesa; e iv) elementos da despesa (KOHAMA, 2001; PISCITELLI; TIMBÓ; ROSA, 2002; MAUSS, 2012).

A classificação por categoria econômica é definida pelos artigos 12 e 13, bem como no Anexo 4, da Lei no 4.320/64. Esta classificação apresenta a discriminação da despesa orçamentária, onde podem ser identificadas duas categorias econômicas, que são: i) despesas correntes; e ii) despesas de capital. A outra classificação é a funcional-programática, onde segundo Kohama (2001, p. 116) o gasto/despesa pública é divido em função e subfunções. O autor afirma que "como Função, deve-se entender o maior nível de agregação das diversas 
BEIRÃO, É. S.; LEITE, M. E.

Execução dos limites mínimos constitucionais de financiamento da educação nos municípios da mesorregião Jequitinhonha

áreas de despesas que competem ao setor público, e como Subfunção, uma partição da função, que visa agregar determinado subconjunto de despesas do setor público".

De acordo com Slomski (2008, p. 319), a classificação por grupos de Natureza de Despesa toma como base "a agregação de elementos de despesa que apresentam as mesmas características quanto ao objeto de gasto". Além dessa, tem a classificação quanto aos elementos das despesas que, segundo Slomski (2008, p.321), "tem por finalidade identificar os objetos de gasto, tais como vencimentos e vantagens fixas, juros, diárias, material de consumo, serviços de terceiros prestados sob qualquer forma, subvenções sociais, obras e instalações, equipamentos e material permanente, auxílios, amortização e outros de que a administração pública se serve para a consecução de seus finn".

Para Giambiagi e Além (2011, p. 33) existem algumas funções que são “típicas de governo". Outras podem ser de responsabilidade da iniciativa privada e algumas podem ser de competência tanto do setor público quanto do privado. Para os referidos autores, caso o governo não assuma algumas funções, "ninguém irá fazê-lo - ou irá fazê-lo de modo parcial ou insatisfatório -, por se tratar da oferta de bens públicos” (GIAMBIAGI e ALÉM, 2011, p.33). As funções a que se referem os autores são as seguintes: (1) Saúde; (2) Educação; (3) Defesa nacional; (4) Policiamento; (5) Regulação; (6) Justiça; e (7) Assistencialismo.

O presente trabalho se propôs a verificar a questão da execução do art. 212 da Constituição de 1988 nos municípios da mesorregião Jequitinhonha, que versa sobre o cumprimento do limite mínimo constitucional da função Educação.

\section{Função Educação}

Segundo Beirão (2017, p. 69), “a Função Educação diz respeito ao conjunto de ações governamentais voltadas à formação intelectual, moral, social, cívica e profissional do indivíduo, preparando-o para uma formação eficaz no processo de desenvolvimento de sua aptidão física e intelectual". A Função é composta por algumas subfunções, a saber: (1) Ensino Fundamental; (2) Ensino Médio; (3) Ensino Profissional; (4) Ensino Superior; (5) Ensino Infantil; (6) Educação de Jovens e Adultos; (7) Educação Especial; e (8) Demais Subfunções - Educação. Quanto ao limite mínimo de investimento na função Educação, o art. 
BEIRÃO, É. S.; LEITE, M. E.

Execução dos limites mínimos constitucionais de financiamento da educação nos municípios da mesorregião Jequitinhonha

212 da Constituição Federal de 1988 o define, tornando obrigatório o seu cumprimento no âmbito da União, Estados e Municípios.

\title{
Art. 212 da CF/88
}

A partir da promulgação da Constituição Federal de 1988, todo ente federado, a União, os Estados, o Distrito Federal e os Municípios, como versa seu art. 212, é obrigado a investir uma determinada porcentagem da receita arrecadada com impostos na manutenção da Função Educação.

\begin{abstract}
Art. 212. A União aplicará, anualmente, nunca menos de dezoito, e os Estados, o Distrito Federal e os Municípios vinte e cinco por cento, no mínimo, da receita resultante de impostos, compreendida a proveniente de transferências, na manutenção e desenvolvimento do ensino.

$\S 1^{\circ}$ A parcela da arrecadação de impostos transferida pela União aos Estados, ao Distrito Federal e aos Municípios, ou pelos Estados aos respectivos Municípios, não é considerada, para efeito do cálculo previsto neste artigo, receita do governo que a transferir;

$\S 2^{\circ}$ Para efeito do cumprimento do disposto no "caput" deste artigo, serão considerados os sistemas de ensino federal, estadual e municipal e os recursos aplicados na forma do art. 213;

$\S 3^{\circ}$ A distribuição dos recursos públicos assegurará prioridade ao atendimento das necessidades do ensino obrigatório, no que se refere a universalização, garantia de padrão de qualidade e equidade, nos termos do plano nacional de educação;

$\S 4^{\circ}$ Os programas suplementares de alimentação e assistência à saúde previstos no art. 208, VII, serão financiados com recursos provenientes de contribuições sociais e outros recursos orçamentários;

$\S 5^{\circ}$ A educação básica pública terá como fonte adicional de financiamento a contribuição social do salário-educação, recolhida pelas empresas na forma da lei; e $\S 6^{\circ}$ As cotas estaduais e municipais da arrecadação da contribuição social do salário-educação serão distribuídas proporcionalmente ao número de alunos matriculados na educação básica nas respectivas redes públicas de ensino (BRASIL, 1988).
\end{abstract}

Fica evidente que, nos termos do dispositivo constitucional acima citado, os entes devem aplicar, anualmente, na educação, no mínimo, $25 \%$ da receita de impostos e transferências constitucionais. Este limite fora reforçado pela Lei de Diretrizes e Bases da Educação (Lei 9.394/96).

A obrigatoriedade do investimento de $25 \%$ das receitas provenientes de impostos e transferências corresponde ao limite mínimo constitucional. A Constituição define limites mínimos para a saúde e para educação, que são as funções de despesas que consomem o maior volume de recursos de um dado Município, Estado ou União. Correspondem a gastos Revista Cerrados, Montes Claros/MG, v.17, n. 2, p. 168-192, jul./dez.-2019. 
BEIRÃO, É. S.; LEITE, M. E.

Execução dos limites mínimos constitucionais de financiamento da educação nos municípios da mesorregião Jequitinhonha

sociais que são dispendidos com o intuito de ofertarem à população o acesso aos serviços nestas áreas.

Um dos problemas mais comuns, no que tange ao cumprimento dos limites mínimos constitucionais da educação e saúde, ocorre no âmbito dos Municípios. Existem Municípios que são considerados como de "pequeno porte" por exercerem relação de dependência entre os Municípios de maior porte, por estes últimos conseguirem prestar serviços públicos à população e atender às necessidades da coletividade.

\section{O problema do limite mínimo constitucional no Brasil}

Em notícia da Todos pela Educação (2018), o professor Amaury Gremaud afirma que "muitas cidades não têm renda própria e dependem, essencialmente, das transferências estaduais e federais. Gremaud afirma que, no Brasil, "temos municípios e municípios", visto que existem os que possuem base econômica forte, com arrecadação de impostos de diferentes áreas. Em contrapartida, existem os que não estão em situação privilegiada e dependem única e exclusivamente do Governo.

Ainda de acordo com Gremaud, a maior parte da renda municipal vem do Fundo de Participação dos Municípios (FPM) e do Imposto sobre Circulação de Mercadorias e Serviços (ICMS) dos Estados. Somadas a estas, existem as transferências voluntárias do governo federal que são veiculadas pelo extinto Ministério da Cultura (MEC) e pelo Fundo Nacional de Desenvolvimento da Educação (FNDE).

Esta situação é muito corriqueira, pois o Brasil é composto de 5.570 Municípios distribuídos em 26 Estados e o Distrito Federal, sendo que, grande parte destes é considerada de pequeno porte e depende das transferências estaduais e federais para a realização de suas funções e o atendimento das demandas da população.

\section{PROCEDIMENTOS METODOLÓGICOS}

Com o intuito de atender ao objetivo traçado para este estudo, foi realizada uma pesquisa de abordagem quantitativa. Quanto aos objetivos, a pesquisa classifica-se em descritiva. O método de pesquisa utilizado é o estudo de caso, sendo que o recorte do trabalho 
BEIRÃO, É. S.; LEITE, M. E.

Execução dos limites mínimos constitucionais de financiamento da educação nos municípios da mesorregião Jequitinhonha

é a mesorregião Jequitinhonha do Estado de Minas Gerais, tendo como amostra os Municípios da referida região.

A amostra em questão pode ser classificada como não probabilística. O instrumento de coleta de dados utilizado foi o levantamento dos dados referentes ao esforço orçamentário com atividades de educação dos municípios da mesorregião Jequitinhonha, disponível na plataforma Índice Mineiro de Responsabilidade Social (IMRS) da Fundação João Pinheiro (FJP). Estes foram coletados e não precisaram ser submetidos a nenhum tipo de ajuste, pois os mesmos encontram-se na forma percentual em relação ao total das despesas públicas executadas pelos governos municipais dos municípios da mesorregião estudada.

\section{Caracterização da mesorregião Jequitinhonha}

A mesorregião Jequitinhonha é uma das doze mesorregiões que compõem o Estado de Minas Gerais. Possui uma área de 50.143, $249 \mathrm{Km}^{2}, 699.482$ habitantes, conforme última estimativa do Instituto Brasileiro de Geografia e Estatística (IBGE) e uma densidade demográfica de 13,9 hab./ $\mathrm{Km}^{2}$. A mesorregião em questão integra o Vale do Jequitinhonha e Mucuri juntamente com outra mesorregião, a do Vale do Mucuri. Juntas estas microrregiões são compostas por 74 municípios.

Esta mesorregião situa-se no nordeste do Estado de Minas Gerais e é conhecida social e economicamente por ser detentora dos mais baixos indicadores sociais, acompanhada da mesorregião do Norte de Minas. Juntas estas mesorregiões são conhecidas por possuírem características do sertão nordestino.

Em contrapartida de sua pobreza econômica e financeira, a mesorregião Jequitinhonha possui uma grande diversidade natural, cultural e étnica. A mesorregião é conhecida por ser detentora de uma exuberante beleza natural. A região não se limita ao estereótipo de pobre ou miserável, possuindo uma cultura rica e diversificada, tenda esta inúmeras manifestações culturais com traços da cultura tradicional indígena e negra. No que diz respeito ao artesanato, a mesorregião também possui uma diversidade de opções, não se restringindo apenas à criatividade de diversos objetos em cerâmica. Além as peças de artesanato da região também são produzidas a partir da palha, bambu, madeira e algodão (NASCIMENTO, 2009). 
BEIRÃO, É. S.; LEITE, M. E.

Execução dos limites mínimos constitucionais de financiamento da educação nos municípios da mesorregião Jequitinhonha

Historicamente, a região pertencia ao Estado da Bahia (até meados do século XVIII), porém fora incorporada ao estado de Minas Gerais, após o período da descoberta de diamantes na região do Município de Diamantina (antigo Tijuco). A Figura 1 apresenta o mapa de localização da mesorregião Jequitinhonha.

Figura 1 - A mesorregião Jequitinhonha

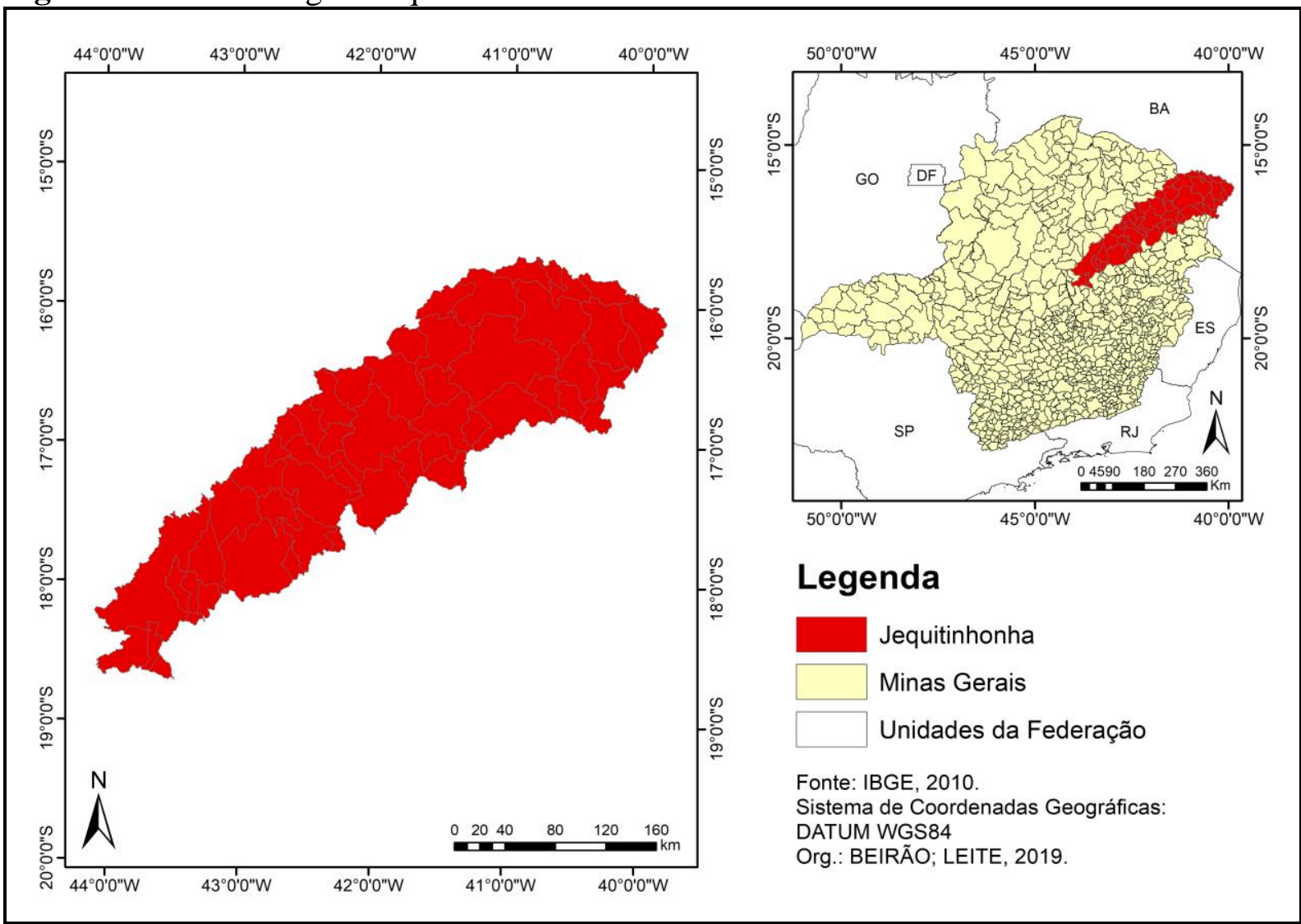

Fonte: Elaborado pelos autores.

A mesorregião Jequitinhonha é composta por 51 Municípios, os quais se situam ao longo do Rio Jequitinhonha. Conforme a regionalização do IBGE, estes são subdivididos em cinco microrregiões, a saber: (1) Almenara; (2) Araçuaí; (3) Capelinha; (4) Diamantina; e (5) Pedra Azul. A Figura 2 apresenta as microrregiões da mesorregião Jequitinhonha.

Estas microrregiões dividem os 51 Municípios que compõem a mesorregião Jequitinhonha. A microrregião de Almenara é composta por 16 municípios, Araçuaí tem 8, Capelinha 14, Diamantina com 8 e Pedra Azul possui 5. O Quadro 1 apresenta a composição detalhada da mesorregião Jequitinhonha. 
BEIRÃO, É. S.; LEITE, M. E.

Execução dos limites mínimos constitucionais de financiamento da educação nos municípios da mesorregião Jequitinhonha

Figura 1 - Microrregiões da mesorregião Jequitinhonha

\section{Legenda

\begin{tabular}{l} 
Diamantina \\
Capelinha \\
\hline Araçuaí \\
Pedra Azul \\
Almenara
\end{tabular}

Fonte: IBGE, 2010

Sistema de Coordenadas Geográficas: DATUM WGS84

Org.: BEIRÃO; LEITE, 2019.

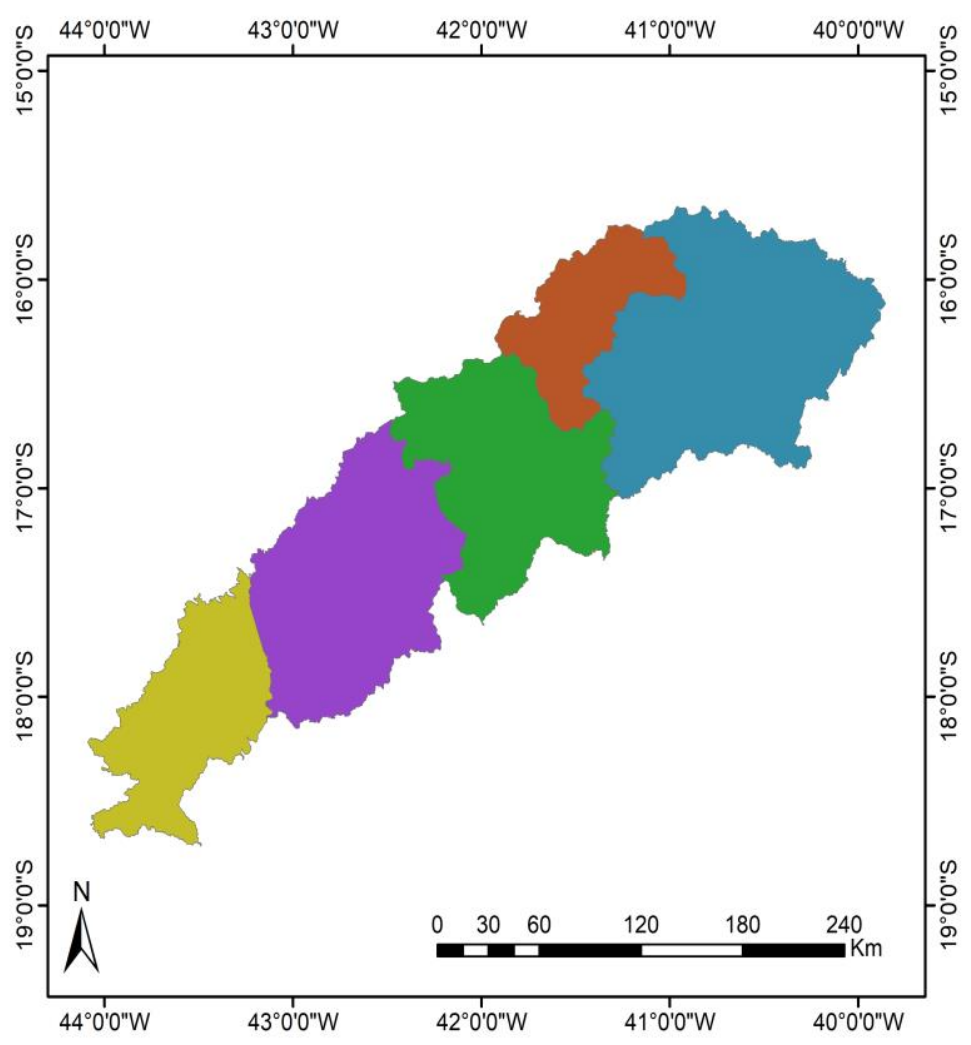

Fonte: Elaborado pelos autores.

Quadro 1 - Composição da mesorregião Jequitinhonha

\begin{tabular}{|l|l|}
\hline Microrregião & Municípios \\
\hline Almenara & $\begin{array}{l}\text { Almenara, Bandeira, Divisópolis, Felizburgo, Jacinto, Jequitinhonha, } \\
\text { Joaíma, Jordânia, Mata Verde, Monte Formoso, Palmópolis, Rio do } \\
\text { Prado, Rubim, Salto da Divisa, Santa Maria do Salto, Santo Antônio } \\
\text { do Jacinto }\end{array}$ \\
\hline Araçuaí & $\begin{array}{l}\text { Araçuaí, Caraí, Coronel Murta, Itinga, Novo Cruzeiro, Padre Paraíso, } \\
\text { Ponto dos Volantes, Virgem da Lapa }\end{array}$ \\
\hline Capelinha & $\begin{array}{l}\text { Angelândia, Aricanduva, Berilo, Capelinha, Carbonita, Chapada do } \\
\text { Norte, Francisco Badaró, Itamarandiba, Jenipapo de Minas, José } \\
\text { Gonçalves de Minas, Leme do Prado, Minas Novas, Turmalina, } \\
\text { Veredinha }\end{array}$ \\
\hline Diamantina & $\begin{array}{l}\text { Couto de Magalhães de Minas, Datas, Diamantina, Felício dos Santos, } \\
\text { Gouveia, Presidente Kubitschek, São Gonçalo do Rio Preto, Senador } \\
\text { Modestino Gonçalves }\end{array}$ \\
\hline Pedra Azul & Cachoeira do Pajeú, Comercinho, Itaobim, Medina, Pedra Azul \\
\hline
\end{tabular}

Fonte: IBGE, 1990. 
BEIRÃO, É. S.; LEITE, M. E.

Execução dos limites mínimos constitucionais de financiamento da educação nos municípios da mesorregião Jequitinhonha

\section{Variável em análise}

A variável utilizada foi o esforço orçamentário em atividades da educação dos municípios da mesorregião Jequitinhonha, extraído da plataforma intitulada Índice Mineiro de Responsabilidade Social (IMRS) da Fundação João Pinheiro (FJP). Foram analisados dados para o período que compreende os anos de 2000 a 2017. De acordo com a FJP (2018), esta variável diz respeito à participação dos gastos orçamentários apresentados nas prestações de contas anuais (PCA) realizadas nas subfunções Ensino Fundamental, Ensino Médio, Ensino Profissional, Ensino Superior, Ensino Infantil, Educação de Jovens e Adultos, Educação Especial e Demais Subfunções - Educação.

\section{ANÁLISE E DISCUSSÃO DE RESULTADOS}

Nesta seção, são apresentados os resultados obtidos através da realização da pesquisa. Os dados são apresentados, analisados, interpretados e confrontados com a literatura apresentada na fundamentação teórica.

A variável em análise é o esforço orçamentário em atividades da educação dos municípios da mesorregião Jequitinhonha referente ao período de 2000 a 2017, medida essa que representa a porcentagem de gastos com educação. Os valores da variável encontram-se distribuídos entre todos os municípios das microrregiões analisadas. No eixo vertical, tem-se a informação referente à porcentagem do esforço orçamentário em atividades da educação dos municípios da mesorregião Jequitinhonha. Já no eixo horizontal, tem-se a quantidade de anos em análise, período que compreende os anos de 2000 a 2017.

Optou-se pelo estabelecimento de um recorte regional, razão pela qual os dados serão analisados por microrregião da mesorregião Jequitinhonha. Esta região fora escolhida baseando-se em estudo realizado pela Assembleia Legislativa de Minas Gerais (ALMG), que evidencia que a mesma é marcada pela forma mais expressiva da pobreza, onde há insuficiência de renda em decorrência do fato de possuir os maiores percentuais de domicílios pobres e de população com menor rendimento. No que tange a dimensão monetária da pobreza, ou seja, aquela relacionada à saúde, educação, habitação, meio ambiente e padrão de 
BEIRÃO, É. S.; LEITE, M. E.

Execução dos limites mínimos constitucionais de financiamento da educação nos municípios da mesorregião Jequitinhonha

vida, a insuficiência de renda encontra-se presente na mesorregião Jequitinhonha (CAON; MAGALHÃES; MOREIRA, 2012).

A variável esforço orçamentário com atividades da educação também foi escolhida por retratar melhor a situação da região que possui uma educação afetada por aspectos de qualidade, desempenho e de ordem estrutural. O Gráf. 1 apresenta a execução dos limites mínimos constitucionais da Educação da microrregião de Almenara no período de 2000 a 2017.

Gráf. 1 - Execução dos limites mínimos constitucionais da Educação na microrregião de Almenara no período de 2000 a 2017

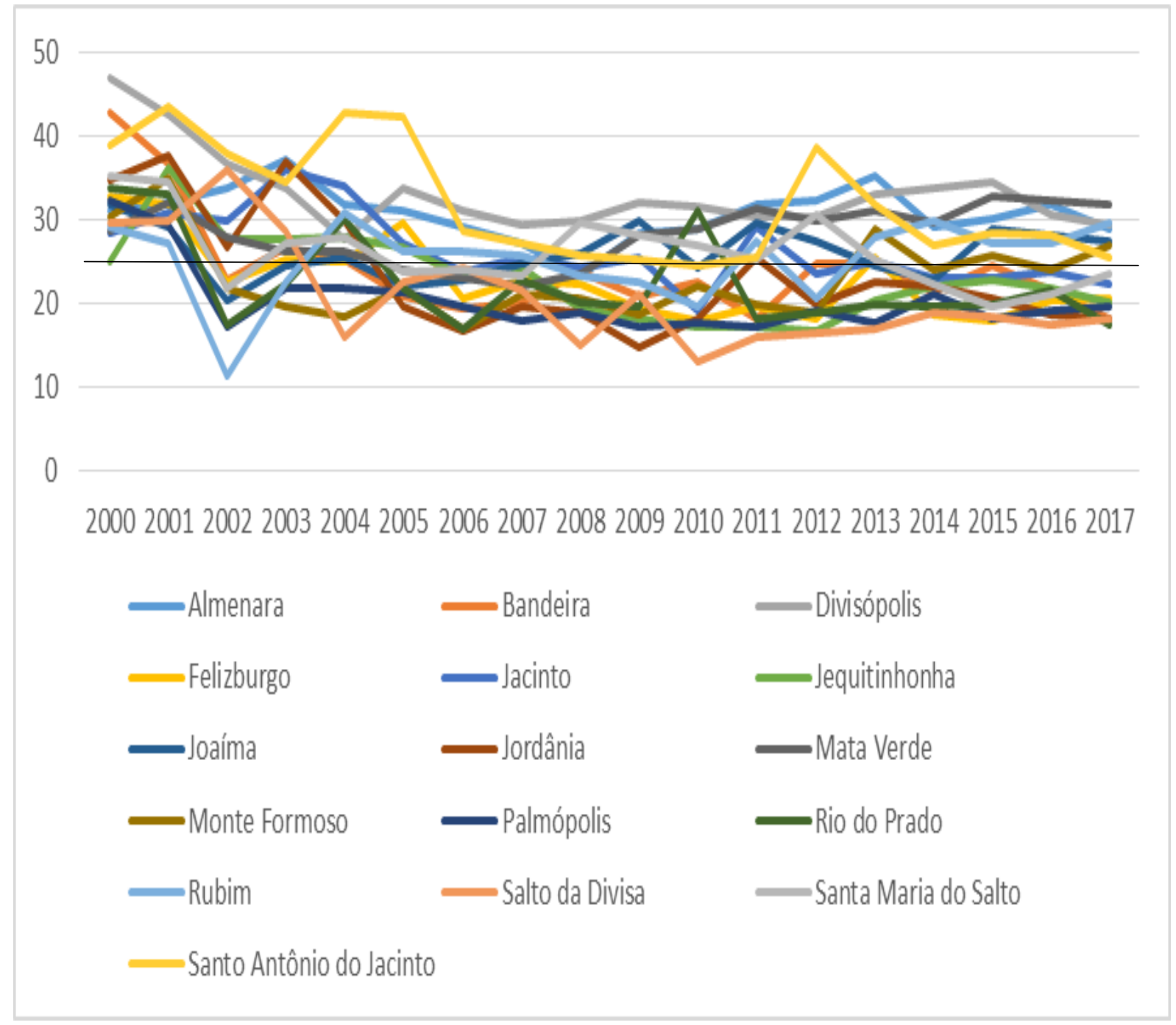

Fonte: IMRS/FJP, 2018. 
BEIRÃO, É. S.; LEITE, M. E.

Execução dos limites mínimos constitucionais de financiamento da educação nos municípios da mesorregião Jequitinhonha

Conforme o Gráf. 1, alguns municípios da microrregião de Almenara atingiram o limite mínimo constitucional de financiamento da educação na maior parte do período que compreende os anos de 2000 a 2017, deixando de cumprir as determinações do art. 212 da Constituição Federal de 1988, como foi o caso de Almenara/MG, Divisópolis/MG, Jacinto/MG, Joaíma/MG, Mata Verde/MG, Rubim/MG, Santa Maria do Salto/MG e Santo Antônio do Jacinto/MG. O município de Jacinto/MG não atingiu o limite mínimo constitucional da educação nos anos 2006, 2008, 2010, 2012 e de 2014 a 2017, Joaíma/MG em 2002, 2003, de 2005 a 2007, 2010, 2013 e 2014, Santa Maria do Salto/MG nos anos 2002, de 2005 a 2007 e de 2014 a 2017, Rubim/MG em 2002, 2003, 2008 a 2010 e 2012, Mata Verde/MG no período de 2005 a 2008, Almenara/MG no ano 2008 e Santo Antônio do Jacinto/MG em 2010. O único município da microrregião de Almenara que não deixou de cumprir o limite em nenhum dos anos da série histórica foi Divisópolis/MG.

No mesmo período, apenas os municípios de Bandeira/MG, Felisburgo/MG, Jequitinhonha/MG, Jordânia/MG, Monte Formoso/MG, Palmópolis/MG, Rio do Prado/MG e Salto da Divisa/MG não atingiram o limite mínimo constitucional da educação na maior parte do período da série histórica. O município de Felisburgo/MG só cumpriu o limite mínimo da educação nos anos de 2000, 2001, de 2003 a 2005 e em 2013, Jordânia/MG no período de 2000 a 2004 e em 2011, Jequitinhonha/MG no período de 2001 a 2005, Monte Formoso/MG nos anos de 2000, 2001, 2013, 2015 e 2017, Bandeira/MG em 2000, 2001, 2003 e 2004, Rio do Prado/MG 2000, 2001, 2004 e 2010, Salto da Divisa/MG de 2000 a 2003 e em Palmópolis/MG nos anos de 2000 e 2001.

O município de Palmópolis/MG, integrante da microrregião de Almenara, foi o que alcançou menor média no período que compreende os anos 2000 a 2017, com percentual médio de 20,47\%, sendo que o conseguiu a maior foi Divisópolis/MG, com 33,26\%. A média do esforço orçamentário com atividades da educação dos municípios da microrregião de Almenara foi de $25,62 \%$.

Na microrregião de Almenara, a maior média anual do esforço orçamentário em atividades da educação dos municípios ocorreu no ano de 2000, com o percentual de 33,94\%, e a menor em 2010 com 22,81\%. A média anual do esforço orçamentário com atividades da educação da microrregião de Almenara foi de 25,62\%. O Gráf. 2 apresenta a execução dos 
BEIRÃO, É. S.; LEITE, M. E.

Execução dos limites mínimos constitucionais de financiamento da educação nos municípios da mesorregião Jequitinhonha

limites mínimos constitucionais da Educação da microrregião de Araçuaí no período de 2000 a 2017.

Gráf. 2 - Execução dos limites mínimos constitucionais da Educação na microrregião de Araçuaí no período de 2000 a 2017

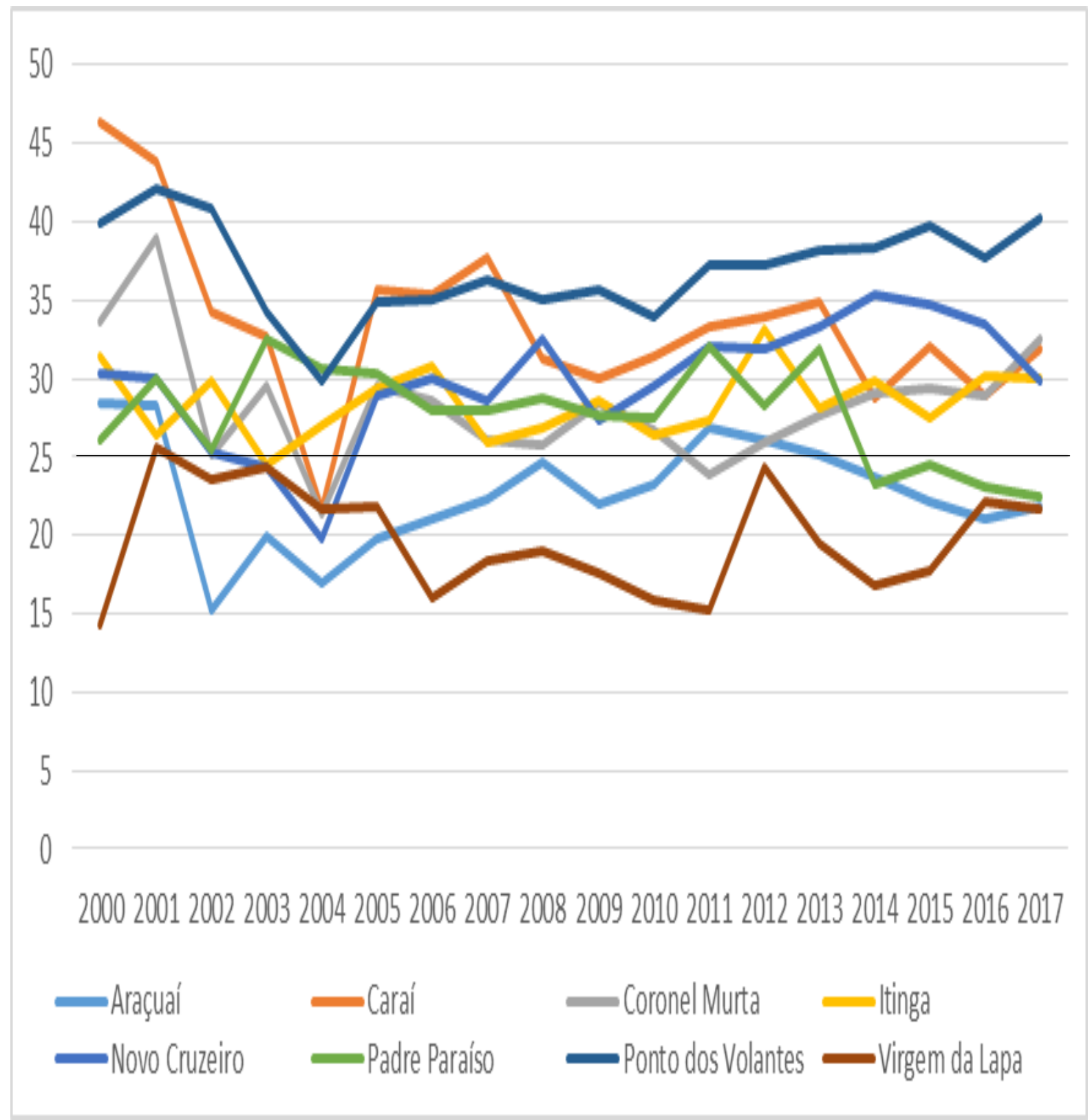

Fonte: IMRS/FJP, 2018.

Conforme o Gráf. 2, os municípios de Caraí/MG, Coronel Murta/MG, Itinga/MG, Novo Cruzeiro/MG, Padre Paraíso/MG e Ponto dos Volantes/MG atingiram o limite mínimo 
BEIRÃO, É. S.; LEITE, M. E.

Execução dos limites mínimos constitucionais de financiamento da educação nos municípios da mesorregião Jequitinhonha

constitucional de financiamento da educação na maior parte do período que compreende os anos de 2000 a 2017. Alguns municípios deixaram de atingir o limite em alguns dos anos da série histórica como foi o caso de Padre Paraíso/MG, no período de 2014 a 2017, Coronel Murta/MG, em 2004 e 2011, Novo Cruzeiro/MG, em 2003 e 2004, Caraí/MG, em 2004 e Itinga/MG em 2003. O único município da microrregião de Araçuaí que não deixou de cumprir o limite em nenhum dos anos da série histórica foi Ponto dos Volantes/MG.

No mesmo período, apenas os municípios de Araçuaí/MG e Virgem da Lapa/MG não atingiram o limite mínimo constitucional da educação na maior parte do período da série histórica, sendo que o primeiro chegou a cumprir o limite nos anos 2000, 2001 e de 2011 a 2013 e o segundo atingiu tal limite apenas no ano 2001.

O município da microrregião de Araçuaí que alcançou menor média no período concernente a série histórica, que compreende os anos 2000 a 2017, foi Virgem da Lapa/MG, com percentual médio de 19,78\%, e aquele que alcançou a maior foi Ponto dos Volantes/MG, com 37,05\%. A média do esforço orçamentário com atividades da educação dos municípios da microrregião de Araçuaí foi de 28,47\%.

Na microrregião de Araçuaí, a maior média anual do esforço orçamentário em atividades da educação dos municípios da microrregião de Araçuaí ocorreu no ano 2000, alcançando o percentual de 33,94\%, e a menor em 2010 com 23,63\%. A média anual do esforço orçamentário com atividades da educação da microrregião de Araçuaí foi de 28,47\%.

Conforme o Gráf. 3, os municípios de Chapada do Norte/MG, Jenipapo de Minas/MG e Turmalina/MG, integrantes da microrregião de Capelinha, atingiram o limite mínimo constitucional de financiamento da educação na maior parte do período que compreende os anos de 2000 a 2017.

Alguns municípios deixaram de cumprir as determinações do art. 212 da Constituição Federal de 1988 em alguns dos anos da série histórica, como foi o caso de Turmalina/MG, nos anos 2006 a 2009, 2011, 2013 e 2015 a 2017, Jenipapo de Minas/MG, de 2003 a 2008, 2010 e 2011 e Chapada do Norte/MG, em 2006. Os únicos municípios da microrregião de Capelinha que não deixaram de cumprir o limite em nenhum dos anos da série histórica foram Angelândia/MG e Minas Novas/MG, respectivamente. 
BEIRÃO, É. S.; LEITE, M. E.

Execução dos limites mínimos constitucionais de financiamento da educação nos municípios da mesorregião Jequitinhonha

Gráf. 3 - Execução dos limites mínimos constitucionais da Educação na microrregião de Capelinha no período de 2000 a 2017

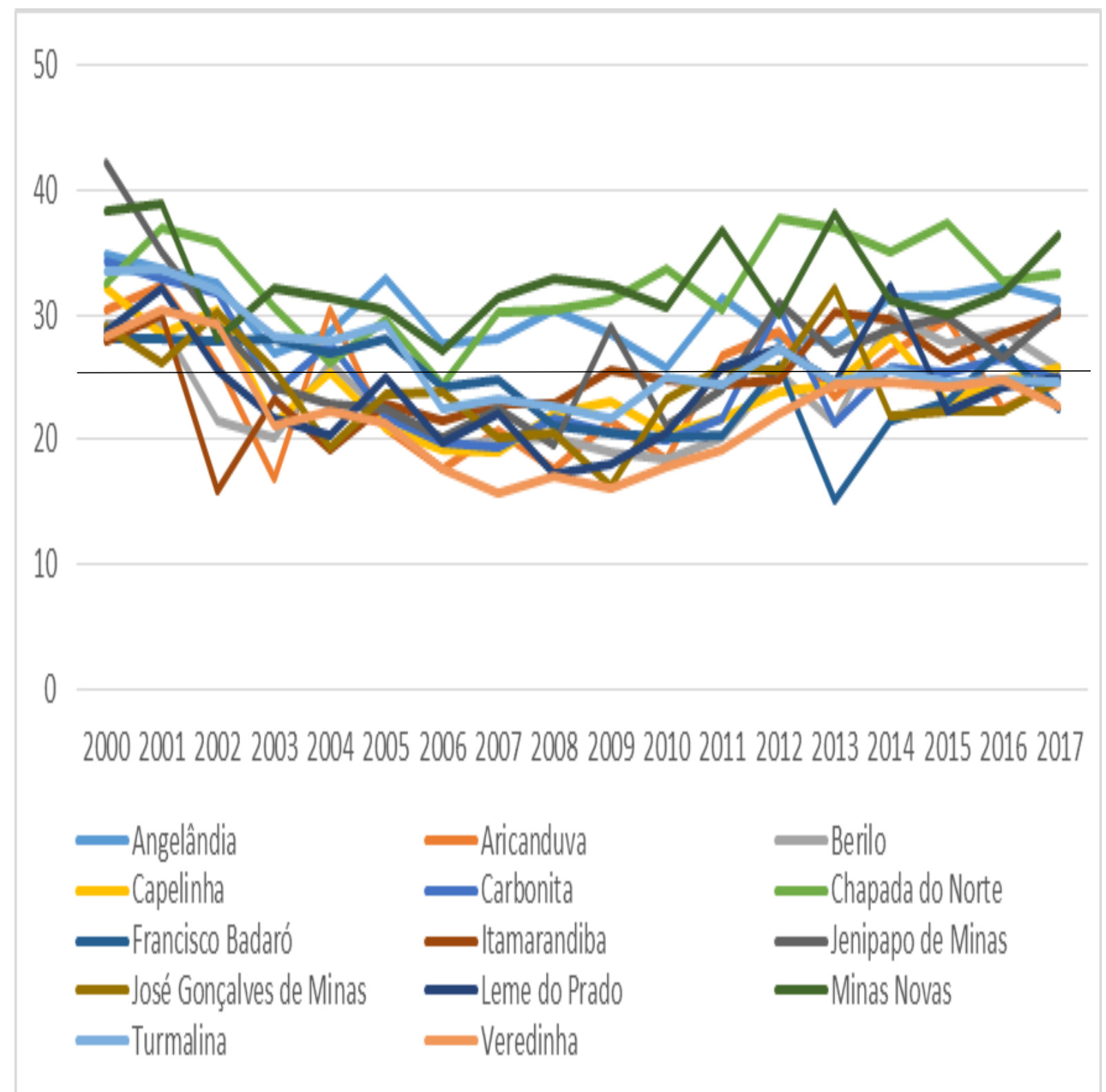

Fonte: IMRS/FJP, 2018.

No mesmo período, os municípios de Aricanduva/MG, Berilo/MG, Capelinha/MG, Carbonita/MG, Francisco Badaró/MG, Itamarandiba/MG, José Gonçalves de Minas/MG, Leme do Prado/MG e Veredinha/MG da mesma microrregião não atingiram o limite mínimo constitucional da educação na maior parte do período da série histórica. $\mathrm{O}$ município de Aricanduva/MG cumpriu o limite mínimo da educação somente nos anos de 2000 a 2002, 2004, 2011, 2012, 2014 e 2015, Berilo/MG, 2000, 2001, 2004, 2012 e 2014 a 
BEIRÃO, É. S.; LEITE, M. E.

Execução dos limites mínimos constitucionais de financiamento da educação nos municípios da mesorregião Jequitinhonha

2017, Carbonita/MG, de 2000 a 2002, 2004, 2012, 2014 a 2016, Francisco Badaró/MG, de 2000 a 2005, 2012 e 2016, Itamarandiba/MG, nos anos de 2000, 2001, 2009, 2013 a 2017, José Gonçalves de Minas/MG, no período de 2000 a 2003 e de 2011 a 2013, Leme do Prado/MG, nos anos de 2000 a 2002, 2005, 2011, 2012 e 2014, Capelinha/MG, no período de 2000 a 2002, 2004, 2014 e 2017 e Veredinha/MG, de 2000 a 2002.

O município de Veredinha/MG, integrante da microrregião de Capelinha, alcançou menor média no período concernente à série histórica, que compreende os anos 2000 a 2017, atingindo o percentual médio de 22,18\%, e a maior foi Minas Novas/MG, com 32,68\%. A média do esforço orçamentário com atividades da educação dos municípios da microrregião de Capelinha foi de 26,09\%.

Na microrregião de Capelinha, a maior média anual do esforço orçamentário em atividades da educação dos municípios da microrregião de Capelinha ocorreu no ano 2000, alcançando o percentual de 33,94\%, e a menor em 2010, com 23,63\%. A média anual do esforço orçamentário com atividades da educação da microrregião de Capelinha foi de $26,09 \%$.

Conforme o Gráf. 4, o município de Senador Modestino Gonçalves/MG atingiu o limite mínimo constitucional de financiamento da educação na maior parte do período, que compreende os anos de 2000 a 2017. Este deixou de cumprir as determinações do art. 212 da Constituição Federal de 1988 nos anos 2014 a 2017.

No mesmo período, os municípios de Couto de Magalhães de Minas/MG, Datas/MG, Diamantina/MG, Felício dos Santos/MG, Gouveia/MG, Presidente Kubitschek/MG e São Gonçalo do Rio Preto/MG não atingiram o limite mínimo constitucional da educação na maior parte do período do período, que compreende os anos de 2000 a 2017.

O município de Presidente Kubitschek/MG cumpriu o limite mínimo da educação somente nos anos de 2000 a 2003, 2005, 2009 e 2016, Couto de Magalhães de Minas/MG, em 2000, 2001 e de 2015 a 2017, Datas/MG, de 2000, 2001 e 2004, Felício dos Santos/MG, de 2000, 2001 e 2012, São Gonçalo do Rio Preto/MG, nos anos de 2000, 2001 e 2014 e Gouveia/MG, nos anos 2000. O único município da microrregião de Diamantina que deixou de cumprir o limite em todos os anos da série histórica foi o município de Diamantina/MG. 
BEIRÃO, É. S.; LEITE, M. E.

Execução dos limites mínimos constitucionais de financiamento da educação nos municípios da mesorregião Jequitinhonha

Gráf. 4 - Execução dos limites mínimos constitucionais da Educação na microrregião de Diamantina no período de 2000 a 2017

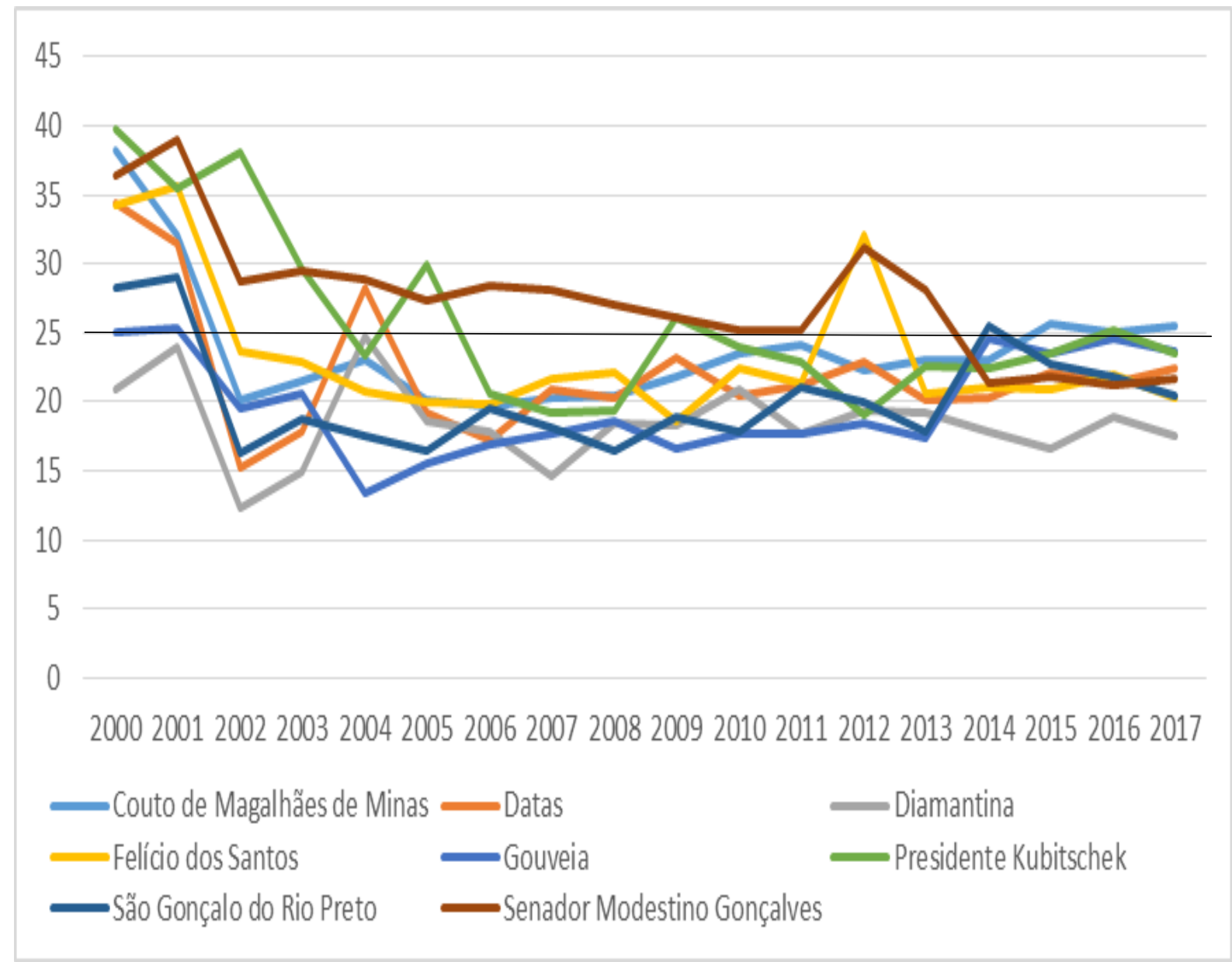

Fonte: IMRS/FJP, 2018.

O município de Diamantina/MG, integrante da microrregião de Diamantina, foi o que alcançou menor média no período concernente a série histórica, que compreende os anos 2000 a 2017, atingindo o percentual médio de 18,48\%, e o maior foi Senador Modestino Gonçalves/MG, com 27,53\%. A média do esforço orçamentário com atividades da educação dos municípios da microrregião de Diamantina foi de 22,68\%.

Na microrregião de Diamantina, a maior média anual do esforço orçamentário em atividades da educação dos municípios da microrregião de Diamantina ocorreu no ano 2000, alcançando o percentual de $32,16 \%$, e a menor em 2006, com 20,03\%. A média anual do esforço orçamentário com atividades da educação da microrregião de Diamantina foi de $22,68 \%$. 
BEIRÃO, É. S.; LEITE, M. E.

Execução dos limites mínimos constitucionais de financiamento da educação nos municípios da mesorregião Jequitinhonha

Nota-se no Gráf. 5 que todos os municípios da microrregião de Pedra Azul atingiram o limite mínimo constitucional de financiamento da educação na maior parte do período, que compreende os anos de 2000 a 2017. O município de Itaobim/MG deixou de cumprir as determinações do art. 212 da Constituição Federal de 1988 nos 2002, 2004, 2007, 2009 a 2011 e 2015, Pedra Azul/MG, de 2004 a 2007, 2009 e 2015, Comercinho/MG, de 2002 a 2004 e 2006, Medina/MG, em 2005, 2006, 2011 e 2017 e Cachoeira do Pajeú/MG, em 2004, 2006 e 2013. Entre os anos 2000 e 2017, não houve municípios da microrregião de Pedra Azul que cumpriram integralmente o limite mínimo constitucional da educação.

Gráf. 5 - Execução dos limites mínimos constitucionais da Educação na microrregião de Pedra Azul no período de 2000 a 2017

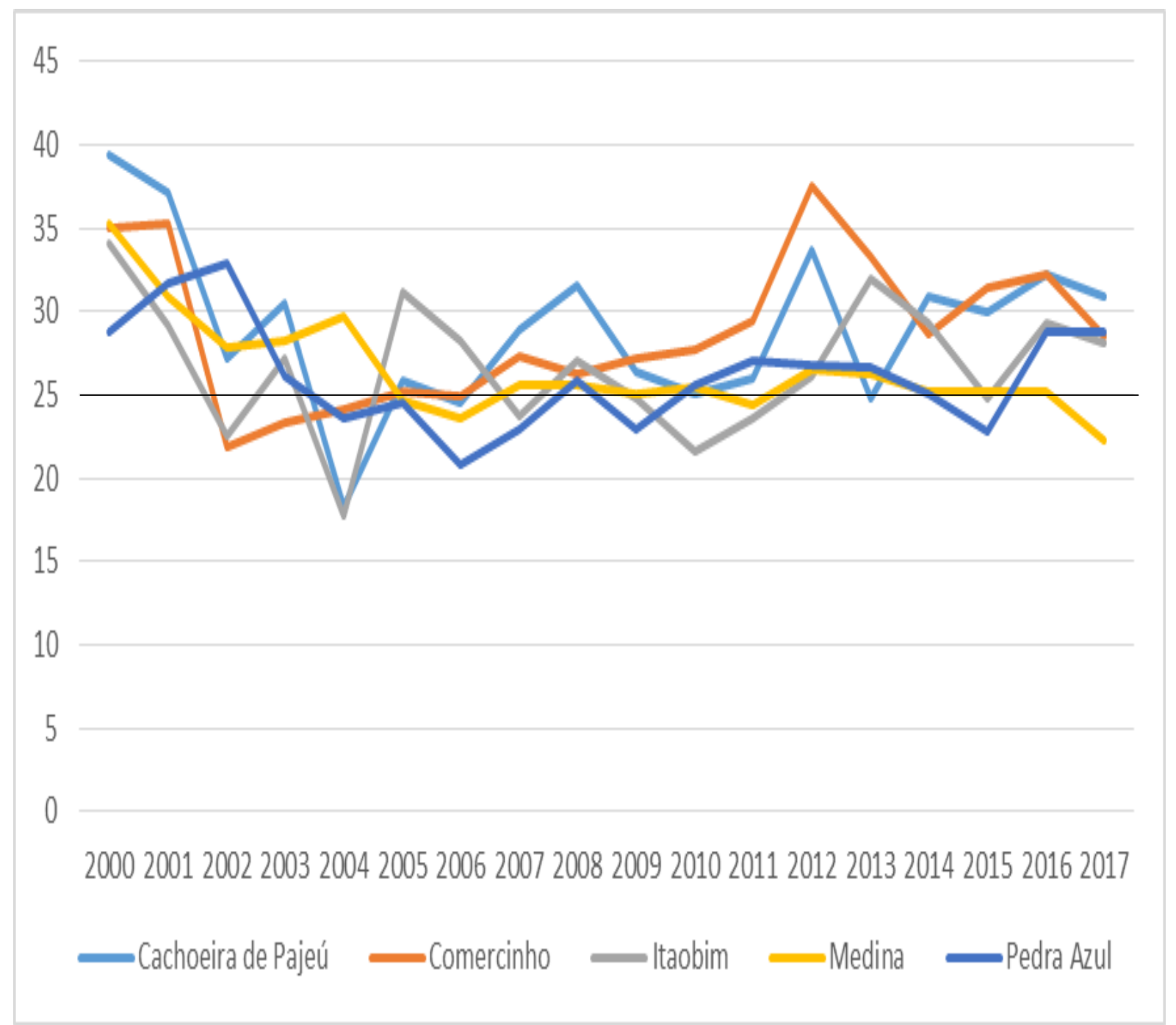

Fonte: IMRS/FJP, 2018. 
BEIRÃO, É. S.; LEITE, M. E.

Execução dos limites mínimos constitucionais de financiamento da educação nos municípios da mesorregião Jequitinhonha

O município da microrregião de Pedra Azul que alcançou menor média no período concernente a série histórica que compreende os anos 2000 a 2017 foi Pedra Azul/MG com percentual médio de $26,21 \%$ e o maior foi Cachoeira do Pajeú/MG com 29,09\%. A média geral do esforço orçamentário com atividades da educação dos municípios da microrregião de Pedra Azul foi de 27,48\%.

Na microrregião de Pedra Azul, a maior média anual do esforço orçamentário em atividades da educação dos municípios da microrregião de Pedra Azul ocorreu no ano 2000, alcançando o percentual de $34,53 \%$, e a menor em 2006 , com $22,70 \%$. A média anual geral do esforço orçamentário com atividades da educação da microrregião de Pedra Azul foi de $27,48 \%$.

No geral, os municípios das cinco microrregiões da mesorregião Jequitinhonha deixaram de cumprir as determinações do art.212 da Constituição Federal de 1988 em quase todos os anos da série histórica, que compreende os anos 2000 a 2017. Na microrregião de Almenara, o município de Divisópolis/MG foi o único a cumprir o limite mínimo em todos os anos da série história. Já o município de Palmópolis/MG foi o que deixou de cumprir por mais vezes, totalizando 16 e tendo cumprido apenas em dois anos.

Na microrregião de Araçuaí, por sua vez, o município de Ponto dos Volante/MG cumpriu o limite em todos os anos da série histórica e Virgem da Lapa/MG cumpriu apenas uma vez. Já na microrregião de Capelinha, os municípios de Angelândia/MG e Minas Novas/MG não deixaram de cumprir o limite mínimo constitucional da educação em nenhum dos anos da série histórica. Já o município de Veredinha/MG cumpriu em apenas 3 anos. O município de Diamantina/MG, integrante da microrregião de Diamantina, não cumpriu o limite mínimo constitucional em nenhum dos anos da série histórica. O município de Senador Modestino Gonçalves/MG deixou de cumprir apenas 4 vezes.

Na microrregião de Pedra Azul, os municípios, em geral, cumpriram o limite mínimo constitucional da educação em mais da metade do período da série histórica que compreende os anos de 2000 a 2017, sendo que o município de Cachoeira do Pajeú/MG deixou de cumprir menos vezes, três para ser exato, e o município de Itaobim/MG descumpriu este limite por sete vezes. 
BEIRÃO, É. S.; LEITE, M. E.

Execução dos limites mínimos constitucionais de financiamento da educação nos municípios da mesorregião Jequitinhonha

As microrregiões de Almenara, Araçuaí, Capelinha, Diamantina e Pedra Azul, integrantes da mesorregião Jequitinhonha, obtiveram média municipal e média anual de $25,62 \%, 28,47 \%, 26,09 \%, 22,68 \%$ e $27,48 \%$, respectivamente.

É possível observar que a microrregião de Diamantina foi a que obteve média menor que o limite mínimo constitucional da educação que é de $25 \%$, pois grande parte dos municípios que integram a microrregião deixou de cumprir o limite na maior parte do período, que compreende os anos 2000 a 2017.

Em todas as microrregiões, observou-se uma redução das porcentagens do esforço orçamentário com atividades da educação no decorrer da série histórica, o que fez com que as médias municipais e anuais fossem reduzidas e se aproximassem ou fossem menores que o limite mínimo estabelecido pela Constituição Federal de 1988, como foi o caso da microrregião de Diamantina.

Ocorre que a maioria dos municípios da mesorregião Jequitinhonha é de pequeno porte no que tange ao desempenho financeiro, à oferta de serviços públicos à população e arrecadação de impostos e depende das transferências do governo estadual e federal, o que pode dificultar no alcance do limite mínimo de investimento na educação, definido pelo art. 212 da Constituição Federal de 1988.

\section{CONSIDERAÇÕES FINAIS}

O presente estudo objetivou verificar a execução do art. 212 da Constituição de 1988 nos municípios da mesorregião Jequitinhonha, no período que compreende os anos de 2000 a 2017. Foi realizada uma análise descritiva, na qual os gráficos contendo as porcentagens do esforço orçamentário com atividades da educação de municípios das microrregiões de Almenara, Araçuaí, Capelinha, Diamantina e Pedra Azul, integrantes da mesorregião Jequitinhonha, foram analisados.

A partir das análises realizadas, é possível concluir que grande parte dos municípios das microrregiões da mesorregião Jequitinhonha não cumpriu o limite mínimo da educação como determina o art. 212 da Constituição Federal de 1988. Pouquíssimos municípios, 4 dos 51 que integram a mesorregião, nunca deixaram de cumprir tal limite, como foi o caso de Angelândia/MG, Divisópolis/MG, Minas Novas/MG e Ponto dos Volantes/MG. 
BEIRÃO, É. S.; LEITE, M. E.

Execução dos limites mínimos constitucionais de financiamento da educação nos municípios da mesorregião Jequitinhonha

A microrregião de Diamantina, por sua vez, é integrada pelo município de Diamantina/MG, o qual deixou de cumprir o limite mínimo da educação em todos os anos da série histórica, que compreende os anos de 2000 a 2017. Este cenário pode ser provocado pelo fato dos municípios da região serem de pequeno porte em termos de prestação de serviços à população, arrecadação de impostos e dispêndio de gastos públicos e dependerem única e exclusivamente dos repasses de transferências do governo estadual e federal.

O que ocorre na mesorregião Jequitinhonha entre os anos de 2000 e 2017 é o descumprimento de uma das determinações da Constituição Federal do Brasil de 1988. Sendo assim, como encaminhamento para estudos futuros envolvendo a temática aqui apresentada, faz-se necessário a realização de novos estudos com vistas a identificar se os gastos com educação e outras funções relacionadas à área social têm cumprido suas funções, se têm suprido as necessidades da população dos municípios da mesorregião Jequitinhonha ou como vÊm sendo utilizados.

\section{AGRADECIMENTOS}

Agradeço o apoio financeiro da Coordenação de Aperfeiçoamento de Pessoal de Nível Superior (CAPES). E a Fundação de Amparo à Pesquisa do Estado de Minas Gerais (FAPEMIG) pela bolsa de pesquisa.

\section{REFERÊNCIAS}

ANGÉLICO, João. Contabilidade pública. 8.ed. São Paulo: Atlas, 1994.

BEIRÃO, Éder de Souza. Análise de despesas públicas orçamentárias: um estudo no município de Montes Claros/MG. Saarbrucken: Novas Edições Acadêmicas, 2017.

BRASIL. Constituição da República Federativa do Brasil de 1988. Brasília: Diário Oficial da União, 1988. Disponível em:

<http://www.planalto.gov.br/ccivil_03/constituicao/constituicaocompilado.htm> Acesso em: 02 de janeiro de 2019.

BRASIL. Lei $\mathbf{N}^{\mathbf{0}}$ 4.320, de 17 de março de 1964. Estatui normas gerais de Direito Financeiro para elaboração e controle dos orçamentos e balanços da União, dos Estados, dos Municípios e do Distrito Federal. Brasília: Diário Oficial da União, 1964. Disponível em: <http://www.planalto.gov.br/ccivil_03/LEIS/L4320.htm> Acesso em: 06 de fevereiro de 2019. 
BEIRÃO, É. S.; LEITE, M. E.

Execução dos limites mínimos constitucionais de financiamento da educação nos municípios da mesorregião Jequitinhonha

BRASIL. Lei $\mathbf{N}^{\mathbf{0}}$ 9.394, de 20 de dezembro de 1996. Estabelece as diretrizes e bases da educação nacional. Brasília: Diário Oficial da União, 1996. Disponível em:

<http://www.planalto.gov.br/ccivil_03/LEIS/L9394.htm> Acesso em: 02 de janeiro de 2019.

CAMPOS, Amauri Ramos de; et al. O cumprimento dos limites constitucionais mínimos de gastos com educação e saúde. Gestão em Foco, n.6, v.1, p.39-50, 2014.

CAON, Ana Rogéria Vitório; MAGALHÃES, Maria Regina Alvares; MOREIRA, Mário César Rocha. Situação da pobreza em Minas Gerais. Revista do Legislativo, n.44, janeiro de 2011/julho de 2012. Disponível em:

<https://www.almg.gov.br/export/sites/default/consulte/publicacoes_assembleia/periodicas/re vistas/arquivos/pdfs/44/04_situacao_da_pobreza_em_Minas_Gerais.pdf $>$ Acesso em: 29 de dezembro de 2018.

COSTA, Frederico Lustosa da; CASTANHAR, José Cezar. Avaliação de programas públicos: desafios conceituais e metodológicos. Revista de Administração Pública, v.37, n.5, 2003.

FUNDAÇÃO JOÃO PINHEIRO. Índice Mineiro de Responsabilidade Social. Belo Horizonte: FJP, 2018. Disponível em: 〈http://imrs.fjp.mg.gov.br/Consultas > Acesso em: 02 de janeiro de 2019.

GIAMBIAGI, Fábio; ALÉM, Ana Claudia Duarte de. Finanças públicas: teoria e prática no Brasil. 4.ed. rev. e atual. Rio de Janeiro: Elsevier, 2011.

INSTITUTO BRASILEIRO DE GEOGRAFIA E ESTATÍSTICA. Divisão regional do Brasil em mesorregiões e microrregiões geográficas. Rio de Janeiro: IBGE, 1990. Disponível em: $<$ https://biblioteca.ibge.gov.br/visualizacao/livros/liv2269_1.pdf > Acesso em: 03 de janeiro de 2019.

KOHAMA, Heilio. Contabilidade pública: teoria e prática. - 8.ed. - São Paulo: Atlas, 2001.

MAUSS, Cézar Volnei. Análise de demonstrações contábeis governamentais: instrumento de suporte à gestão pública. São Paulo: Atlas, 2012.

NASCIMENTO, Elaine Cordeiro do. Vale do Jequitinhonha: entre a carência social e a riqueza cultural. Contemporâneos: Revista de Artes e Humanidades, n.4, maio-out. 2009.

PISCITELLI, Roberto Bocaccio; TIMBÓ, Maria Zulene Farias; ROSA, Maria Berenice. Contabilidade pública: uma abordagem da Administração Financeira Pública. - 7. ed. rev., ampliada e atualizada até fevereiro de 2002 - São Paulo: Atlas, 2002.

SLOMSKI, Valmor. Manual de contabilidade pública: um enfoque na contabilidade municipal, de acordo com a Lei de Responsabilidade Fiscal. - 2.ed. - 5. reimpr. - São Paulo: Atlas, 2008.

STIGLITZ, Joseph. Economics of the public sector. Londres, Norton\&Company, 1986. 
BEIRÃO, É. S.; LEITE, M. E.

Execução dos limites mínimos constitucionais de financiamento da educação nos municípios da mesorregião Jequitinhonha

TODOS PELA EDUCAÇÃO. Municípios devem gastar no mínimo $25 \%$ de seus orçamentos com educação. São Paulo: Todos pela Educação, 2018. Disponível em: $<$ https://www.todospelaeducacao.org.br/conteudo/municipios-devem-gastar-no-minimo-25-

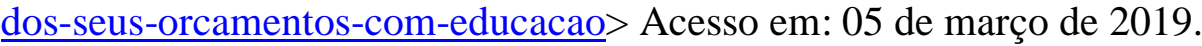

\section{Autores}

Éder de Souza Beirão - Possui Graduação em Administração pela Universidade Estadual de Montes Claros (UNIMONTES). Atualmente cursa Mestrado pelo Programa de PósGraduação em Desenvolvimento Social da Universidade Estadual de Montes Claros (UNIMONTES).

Marcos Esdras Leite - Possui Graduação em Geografia pela Universidade Estadual de Montes Claros (UNIMONTES), Mestrado e Doutorado em Geografia pela Universidade Federal de Uberlândia (UFU). Atualmente é Professor do Programa de Pós-Graduação em Desenvolvimento Social, do Programa de Pós-Graduação em Geografia do Departamento de Geociências da Universidade Estadual de Montes Claros (UNIMONTES).

Artigo recebido em: 12 de abril de 2019.

Artigo aceito em: 03 de junho de 2019.

Artigo publicado em: 29 de outubro de 2019. 